\title{
O ENTRE-LUGAR DOS DESAPARECIDOS POLÍTICOS EM $K$. RELATO DE UMA BUSCA E VOCE VAI VOLTAR PRA MIME OUTROS CONTOS, DE BERNARDO KUCINSKI
}

\author{
Cristina Napp dos Santos ${ }^{35}$ \\ Claudia Lorena Fonseca ${ }^{36}$
}

Resumo: Este trabalho confronta três textos da produção literária do autor Bernardo Kucinski, K. Relato de uma busca, "O velório" e "Joana". Além de compartilharem a característica de terem como pano de fundo a Ditadura Civil-Militar no Brasil, o romance e os dois contos abordam o drama dos familiares frente ao desaparecimento forçado dos militantes que se opunham ao regime. Retratam ainda o luto, a melancolia e de que forma a ausência do corpo interfere na concretização da morte no imaginário e nos rituais de luto. Ao propor uma análise interpretativa e comparativa do romance e dos contos, agregando as contribuições de Freud e Kristeva, bem como pesquisas antropológicas referentes a luto e rituais fúnebres, o artigo reflete acerca da importância do corpo para o processo de luto na cultura ocidental.

Palavras-chave: Ditadura brasileira; desaparecimento forçado; luto; rituais fúnebres.

Abstract: This paper compares three texts of Bernardo Kucinski's literary production, K. Relato de uma busca, "O velório" and "Joana". In addition to sharing the characteristic of having the Civil-Military Dictatorship in Brazil as context, the novel and the two short stories deal with the reaction of family members to the forced disappearance of militants who opposed the regime. Also, they portray the mourning, the melancholy, and the way that the absence of the body interferes in the concretization of death in the imaginary and in the rituals of mourning. By proposing an interpretive and comparative analysis of the novel and the short stories,

\footnotetext{
${ }^{35}$ Mestranda do Programa de Pós-graduação em Letras - Mestrado Acadêmico em Literatura Comparada da Universidade Federal de Pelotas - UFPel. Bolsista CAPES.

${ }^{36}$ Doutora em Literatura Comparada. Professora Adjunta do Centro de Letras e Comunicação e do Programa de Pós-graduação em Letras da Universidade Federal de Pelotas - UFPel.
} 
144 | Cristina Napp dos Santos e Claudia Lorena Fonseca

adding the contributions of Freud and Kristeva, as well as anthropological researches related to mourning and funeral rituals, this work reflects on the importance of the body to the process of mourning in Western culture.

Keywords: Brazilian dictatorship; forced disappearance; mourning; funeral rituals.

\section{Introdução}

Durante o período ditatorial, compreendido entre as décadas 1960 e 1980, o Brasil se viu diante da barbárie do sistema repressivo. Em nome de um conjunto de ideais conservadores, de um nacionalismo indefectível, e da caça ao comunismo, a ditatura perseguia e matava aqueles que se opunham ao regime e eram considerados, portanto, "inimigos internos" (BENEVIDES, 2014).

Tendo vivido esse período e participado ativamente de seus eventos, é basicamente sobre esse contexto que o escritor, jornalista e cientista político, Bernardo Kucinski, vem escrevendo nos últimos trinta anos. Nos últimos dez, despiu a camisa de jornalista e vestiu a de escritor (KUCINSKI, 2016) aderindo à ficção e lançando três obras sobre a ditadura civil-militar: K. Relato de uma busca (2011); Você vai voltar pra mim (2014) e Os visitantes (2016).

No seu primeiro romance, K. Relato de uma busca, o autor se vale da experiência familiar para construir uma narrativa polifônica na qual um pai vai definhando ao tentar encontrar informações sobre o desaparecimento forçado da filha. Ele, um judeu que emigrou para o Brasil no período da Segunda Guerra Mundial, se dedicava ao í́diche quando do sumiço de A. Ela, professora universitária do departamento de química da Universidade de São Paulo, e pertencente a um grupo clandestino de resistência ao governo, havia sido vítima de um sequestro praticado pelos agentes que estavam a serviço do regime militar.

Ainda que a história esteja ambientada na última década de 70, a temática da ditadura no Brasil ainda é (e deve ser) trabalhada como contemporânea, por se tratar de um passado que o Estado veio reprimindo ao longo dos anos. A falta de elaboração desse passado culminou numa amnésia coletiva que acaba sendo ainda mais problemática no caso dos desaparecimentos políticos pela dificuldade em sua apreensão, já que se trata de um crime continuado, que não se encerra, não se resolve, tampouco se repara. 
O entre-lugar dos desaparecidos políticos em K. Relato de uma busca e

Você vai voltar pra mim e outros contos, de Bernardo Kucinski| 145

A fim de lutar contra esse esquecimento, por ele chamado de Alzheimer nacional (2014a, p.12), Bernardo Kucinski insiste em relembrar os incontáveis prejuízos humanos causados por essa época. Para isso, volta a trabalhar sobre a ditadura civil-militar em Você vai voltar pra mim e outros contos. Nessa compilação de contos inspirados em relatos ouvidos ao assistir a uma sessão da Comissão Nacional da Verdade $(\mathrm{CNV})^{37}$, o autor traça um panorama acerca da atmosfera dos tempos de opressão, de modo que os casos de desaparecimento não deixam de estar presentes, sendo centrais em dois dos quase trinta contos: "O velório" e "Joana". Mesmo compartilhando angústias semelhantes, os familiares em cada um dos contos reagem de diferentes maneiras, ora aproximando, ora distanciando suas narrativas da vivência de $K$.

Assim, este trabalho confronta esses três textos e reflete acerca da reação dos familiares frente ao desaparecimento forçado dos militantes que se opunham ao regime. A partir disso, focaliza no luto e na forma em que a ausência do corpo interfere na concretização da morte no imaginário e nos rituais fúnebres. Para embasar a discussão, agrega-se à análise os estudos acerca de luto e melancolia propostos por Freud e Kristeva, bem como contribuições de estudos antropológicos sobre a importância dos rituais fúnebres para a superação da perda.

\section{K. Relato de uma busca}

Publicado pela primeira vez em 2011, mais de 45 anos depois do golpe militar, e no mesmo ano em que foi fundada a Comissão Nacional da Verdade, delegação responsável por investigar as violações de direitos humanos no período ditatorial, $K$. Relato de uma busca aborda de que forma esses crimes de Estado afetaram aqueles que não estavam diretamente envolvidos na luta contra o governo, sobretudo os familiares dos desaparecidos políticos.

A narrativa gira em torno da saga kafkaniana de K., que busca sua filha desaparecida. Mesmo se tratando de um caso de tortura e morte, A.

37 Criada pela Lei 12528/2011 e instituída em maio de 2012, a Comissão Nacional da Verdade se trata de uma comissão temporária que atuou entre 2012 e 2014 com o objetivo de promover a apuração e o esclarecimento público das violações de direitos humanos praticadas pelo Estado brasileiro entre 1946 e 1988, contribuindo para o preenchimento das lacunas existentes na história do país em relação a esse período e, ao mesmo tempo, para o fortalecimento dos valores democráticos. 
146 | Cristina Napp dos Santos e Claudia Lorena Fonseca

continuava na lista de desaparecidos. Sendo considerada uma desaparecida política, não há o reconhecimento de sua morte, o que a coloca em uma situação que não pode ser plenamente categorizada. Esse não reconhecimento reflete em K., já que ele não consegue concretizar os rituais de luto, não readequando sua vida à nova realidade, ficando preso à sua perda.

Mas a obra de Kucinski não se configura como a narrativa do sofrimento de A., nem da recuperação de sua memória, já que no início e ao longo de todo o romance $\mathrm{K}$. se depara com a impossibilidade de reconstituir essa memória, uma vez que reconhece que antes do desaparecimento já havia um distanciamento entre os dois, como ilustra o trecho:

\begin{abstract}
Quando [K.] deparou com fotografias da filha em situações e cenários que nunca imaginara, percebeu de novo o quanto da vida da filha ignorara e ainda ignorava. Além da pose com as duas amigas, que ele conhecia bem, e as fotografias previsíveis no trabalho, trajando o avental branco do laboratório, havia outras, surpreendentes (KUCINSKI, 2014a, p. 114).
\end{abstract}

A obra trata, portanto, da ausência e, como o subtítulo sugere, da busca de um pai por informações precisas acerca do local e circunstância do assassinato da filha. Para além disso, ilustra a angústia causada pela falta do corpo para fins de sepultamento e rituais de luto, já que essa ausência punha à prova a certeza da morte.

\title{
Você vai voltar pra mim e outros contos
}

Lançado alguns anos depois, em 2014, Você vai voltar pra mim e outros contos se configura como uma coletânea de contos que quebra a expectativa do leitor diante do título, ao apresentar vinte e oito pequenas narrativas, muitas vezes permeadas por um tom irônico, que se conectam por também se desenrolarem durante o período de repressão.

Sem apelação emotiva e com uma linguagem crua e direta, dentro dos limites impostos pelo gênero conto, Kucinski apresenta histórias cujos narradores são ora heterodiegéticos, ora homodiegéticos, e mostram de que forma o sistema acabou afetando distintamente as mais variadas camadas da sociedade. Assim, focaliza em diferentes pontos de vista, como os familiares dos militantes, tanto os que apoiavam a luta contra o 
O entre-lugar dos desaparecidos políticos em K. Relato de uma busca e

Você vai voltar pra mim e outros contos, de Bernardo Kucinski| 147

regime, quanto os que não entendiam o afastamento em prol de um ideal; os que não eram atuantes nos movimentos, mas acabaram sendo torturados em função de estabelecer vínculos com membros dos grupos; os próprios militantes, presos, torturados ou exilados.

Para este trabalho, destacamos os contos "O velório" e "Joana", pois esses estabelecem uma maior relação com $K$., ao apresentarem como epicentro a relação da família com o desaparecimento da vítima direta. Nessas narrativas, em função da limitação do gênero textual, não temos tantas informações quanto em K.. Trata-se de um recorte, a captura de um momento, uma vez que no conto, assim como na fotografia, apresenta-se a

necessidade de escolher e limitar uma imagem ou acontecimento que sejam significativos, que não só valham por si mesmos, mas também sejam capazes de atuar no espectador ou no leitor como uma espécie de abertura, de fermento que projete a inteligência e sensibilidade em direção a algo que vai muito além do argumento visual ou literário contido na foto ou no conto (CORTÁZAR, 1974, p. 151-152)

Mas é através dessa abertura, que no primeiro conto tratado, "O velório", ao fim do primeiro parágrafo, já temos pistas de que esse velório mencionado no título não é um velório comum, mas um enterro especial.

Para o velório, [o velho Antunes] encomendou quatro velas grandes em castiçais de prata sobre colunas de alabastro. E uma coroa de flores com faixa de seda azul e branca na qual mandou escrever: "Ao Roberto, dos seus pais, tios e irmãs, que nunca te esqueceram” (KUCINSKI, 2014b, p. 49).

A indicação de que não se trata de um funeral comum se dá em função da inscrição presente na coroa de flores, pois ao pedir que o verbo esquecer fosse conjugado no passado, Antunes deixa claro que a família já estava convivendo com a perda de seu filho. Se em um primeiro momento o leitor tem uma sensação de estranhamento em relação ao velório, ao longo do conto entendemos que isso ocorre pois, contrariando a lógica, não há um cadáver a ser velado, o que se explica pelo fato de o 
148 | Cristina Napp dos Santos e Claudia Lorena Fonseca

morto ser um jovem que se opunha e atuava contra o Estado, estando, portanto, na lista de desaparecidos.

No que diz respeito ao segundo conto, o estranhamento também se faz presente, pois antes de contar a história de Joana o narrador nos convida a observá-la, a abandonar a ideia de que se trata de uma pessoa comum. Joana é uma mulher idosa que uma ou duas noites por semana percorre as ruas de uma cidade inominada buscando o marido desaparecido

O marido era metalúrgico e se chamava Raimundo. Católico praticante como ela. Vieram do Nordeste em busca de uma vida um pouco melhor em São Paulo. Já tinham então os dois filhos. Aqui Raimundo se ligou a um grupo de Ação Popular que organizava operários nas fábricas.

Um dia, bem cedo, a polícia foi à casa deles e levou Raimundo. Sem mandado de prisão, sem nada. Soube-se depois que ele foi espancado de modo tão brutal que ele morreu no mesmo dia. Seus gritos eram ouvidos em outras celas. Para ocultar o homicídio, no caso doloso e qualificado, pois acompanhado do crime acessório de abuso de autoridade, a polícia cometeu outro crime, o de ocultamento de cadáver. Sumiram com o corpo de Raimundo. Tudo isso comprovado, depois que acabou a ditadura, por documentos e depoimentos em várias comissões. Só não se sabe, nunca se soube, para onde levaram o corpo e como se desfizeram dele (KUCINSKI, 2014b, p. 59).

Ainda que a morte de Raimundo tenha sido divulgada, e o cardeal da igreja de Joana tenha confirmado o seu assassinato, Joana se nega a aceitar a morte do marido, alegando que só aceitará a morte como oficial quando puder reconhecer o corpo.

O luto e o entre-lugar dos desaparecidos políticos e de seus familiares em K. Relato de uma busca, "O velório" e "Joana"

Tanto no romance quanto nos contos, se apresenta ao leitor uma atmosfera de intensa crueldade e desrespeito à dignidade humana, em um cenário marcado pelo abuso de poder e pela impunidade. Se a 
O entre-lugar dos desaparecidos políticos em K. Relato de uma busca e

Você vai voltar pra mim e outros contos, de Bernardo Kucinski| 149

perseguição política e a tortura e morte já se caracterizam como atos de extrema violência, no caso dos desaparecimentos agrava-se essa crueldade pela situação de irresolução, pois de acordo com Araújo Lima,

a noção de desaparecido implica a de suspensão. O desaparecido é aquele que está para ser, porém não é. É algo irresoluto. Está suspenso. Está fixado no tempo sem poder resolver-se. É a situação dos desaparecidos. Não estando vivos nem mortos, estão, na realidade, vivos e mortos. Sua situação caracteriza-se pelo que Victor Turner denominou de liminaridade. Somente seu aparecer na forma de cadáver é capaz de por fim a essa indefinição (ARAÚJO LIMA, 2012, p. 987).

Considerando-se esses aspectos, podemos dizer que o lugar que ocupa um desaparecido no meio em que se insere, é na verdade um entre$\operatorname{lugar}^{38}$, uma situação intermédia entre a vida e a morte, de concomitância entre vida e morte de um sujeito que, na ausência da materialidade do corpo a ser reconhecido e sepultado, segue existindo. A situação de coexistência entre vida e morte acaba por colocar também seus familiares em um entre-lugar, já que eles não conseguem concretizar a morte de seus entes queridos em seu imaginário, impossibilitando a readequação de suas vidas à nova realidade. Essa condição intermédia se configura como consequência da melancolia que se estabelece, a qual Kristeva define como "morte viva, carne cortada, sangrante, tornada cadáver, ritmo diminuído ou suspenso, tempo apagado ou dilatado, incorporado na aflição" (1989, p. 11).

Tanto no caso dos desaparecidos quanto no caso dos familiares, o entre-lugar se configura como um constructo cultural que parte da noção de que a morte não é apenas o fim da vida, mas uma passagem para o mundo dos mortos, que pode variar de acordo com a crença de cada grupo (RODOLPHO, 2004, p.142), mas que exige um corpo para que seja efetivada. Dessa forma, a crença acaba se constituindo em fator fundamental para estabelecer a relação das famílias com a morte e, tanto em K., quanto em $\mathrm{O}$ Velório e em Joana, a religiosidade aparece bastante marcada.

${ }^{38}$ Utilizamos o conceito de entre-lugar, tal como formulado por Silviano Santiago. 
Embora não tenhamos acesso à crença dos desaparecidos de Kucinski no que diz respeito à forma como encaravam a morte, em K., através do relato de Jesuína, a faxineira no centro clandestino de tortura para onde A. foi levada, somos informados que a última palavra da prisioneira teria sido a declaração de seu nome completo. "Disse assim recitado como quem sabe que vai morrer e quer deixar o nome, para os outros saberem" (KUCINSKI, 2014a, p. 129 - 130). Essa reação de A. diante da expectativa da morte não nos permite, de fato, formular uma hipótese sobre a importância que ela atribuía aos rituais fúnebres, embora possamos supor que, dada a sua condição judaica, ela compartilhe dos dogmas professados pelo judaísmo. No entanto, o que talvez, sim, possamos pensar, é que sua reação se trata da maneira por ela encontrada de anunciar quem era, na tentativa de que fosse localizada, para que mesmo morta não desaparecesse por completo.

Os rituais de sepultamento igualmente simbolizam a separação do mundo dos vivos; estes devem zelar pelo bom encaminhamento dos ritos segundo os costumes do grupo. O não-cumprimento destas prescrições pode ocasionar resultados, como o destino da alma que pode errar sobre a terra, ou ocasionar outros riscos para o mundo dos vivos (RODOLPHO, 2004, p. 142).

No entanto, se há dúvidas quanto aos sentimentos de A., de Roberto e de Raimundo em relação aos rituais, essas deixam de existir quando se trata de K., Antunes e Joana. Para o pai de A., sem um ritual de sepultamento a passagem da filha ao mundo dos mortos não acontece, ou seja, ela não termina de morrer. Judeus ou não, os algozes de A., também sabem disso, pois compartilham com K. os mesmos constructos, o mesmo imaginário, o que alimenta seu sadismo, permitindo a extensão da tortura infligida à filha, agora aplicada ao pai, atingido nas camadas mais profundas de seu ser, o que torna incessante sua busca.

Mineirinho, você viu como deu certo o lance com o Fogaça? Só que não é nada do que você está pensando, Mineirinho. $O$ velho não veio porque acreditou, Mineirinho. Esse velho é esperto. Ele veio porque tinha que vir. Ele tinha que vir, entendeu? Mineirinho, aí é que está o truque, a psicologia. Ele tinha que vir, mesmo não acreditando. E sabe por quê? Porque se ele está correndo 
O entre-lugar dos desaparecidos políticos em K. Relato de uma busca e

Você vai voltar pra mim e outros contos, de Bernardo Kucinski| 151 atrás desses figurões, mesmo depois desse tempo todo, é porque não quer aceitar que a filha já era. Se recusa. Daí se agarra em qualquer coisa, mesmo sabendo que é armação. Não pode deixar de ir, de tentar. Sabe de uma coisa, Mineirinho, foi uma puta ideia essa que eu tive (KUCINSKI, 2014a, p. 70-71).

No que diz respeito a Antunes, este entende o ritual de sepultamento como fundamental, no entanto, já não tem mais tempo para esperar ou buscar, pois completados seus noventa anos, sabe que são remotas as possibilidades de ter de volta o filho com vida ou mesmo de receber seu corpo morto. Então decide proporcionar ao filho, e a ele mesmo, o necessário ritual de sepultamento, pois entende que "Os mortos têm de ser enterrados" (KUCINSKI, 2014, p. 50). A ausência da materialidade do corpo de Roberto é substituída e simbolizada pela materialidade do caixão, das roupas que foram do filho, e de seu retrato, posto sobre o caixão. É à foto de Roberto que todos se dirigem, familiares, amigos e autoridades, a fim de prestar as últimas homenagens ao falecido, o que certamente entendem se tratar de uma necessidade do pai, mas de certa forma também deles mesmos, inseridos que estão naquele contexto histórico-social. Trata-se de um ritual meramente simbólico que transcorre, no entanto, de forma bastante tradicional: os familiares chegam aos poucos, cumprimentam os pais de Roberto, circulam bandejas com sanduíches, broas de milho e cuscuz de sardinha, os músicos reverenciam o retrato de Roberto na parede, depois em frente a sua casa, os demais presentes conversam na sala. Além disso, o evento causa bastante comoção na comunidade, não apenas a comoção natural em situações de morte cotidianas, mas a consciência do drama que diz respeito não apenas àquele pai, mas a todos. Há um elemento a mais a comover os presentes, todos sabem o que aconteceu, ninguém fala, não podem e não devem: pronunciar palavra quebraria o acordo tácito entre eles e arriscaria o sucesso da experiência agônica que vivem. Cumprem então o seu papel.

Às três da tarde tem-se a impressão de que todos os viventes da cidade estão no velório de Roberto, inclusive os cachorros e os gatos. Comentam que nunca houve um velório tão concorrido. Não se vê ninguém nas outras ruas, 
na praça da matriz, na rodoviária. Virou cidade fantasma (KUCISNKI, 2014b, p. 54).

Quanto à Joana, esta sequer cogita proporcionar ao marido um ritual fúnebre. Ela nega essa morte. Para Joana, a não materialidade de um corpo significa que o desaparecimento não se configura em morte, agarrando-se ao significado literal da palavra como forma de preservação da vida, tanto a de seu marido quanto a sua própria, traduzida, nesse caso, como possibilidade de continuar existindo. "Diz que só vai se considerar viúva no dia em que trouxerem o atestado de óbito de Raimundo e mostrarem sua sepultura" (KUCINSKI, 2014b, p. 59). À Joana, o Estado concede um atestado de óbito, o que nem sempre ocorria nessas situações. No entanto ela não o aceita, formulando hipóteses sobre o desaparecimento de Raimundo, como a perda da memória causada pelo espancamento, o que o faria andar sem rumo ainda pelas ruas da cidade aguardando que alguém o encontrasse e o reconduzisse a sua casa e ao convívio dos seus.

Portanto, considerando os três casos, e suas formas distintas de administração do conflito, podemos dizer que apenas Antunes experimenta algum conforto em relação ao desaparecimento de seu ente querido, pois ao conseguir cumprir de forma convincente o ritual de sepultamento do filho, segundo os princípios de sua religião, pode passar finalmente à etapa do luto convencional, saindo portanto do entre-lugar em que se encontrava. Assim, ao contrário do que ocorre com K. e com Joana, Antunes consegue ressignificar sua vida, ou que que resta dela, pelo fato de ter podido concretizar a morte do filho, proporcionando-lhe a transição para o mundo dos mortos.

[Antunes] sente-se exausto, mas feliz. Seu sonho de tantos anos finalmente se realiza; já pode morrer em paz. E toda a cidade compreendeu. Isso foi o mais importante. Toda a cidade. Até o padre Gonçalves, que primeiro lavou as mãos, depois deu a bênção (KUCINSKI, 2014b, p. 55).

Antunes traduz por felicidade o sentimento de libertação que experimenta ao final da experiência de sepultamento do filho. A breve passagem pelo luto tradicional e sua conclusão ressignificam sua vida, pois "quando o trabalho de luto se conclui, o ego fica outra vez livre e desinibido" (FREUD, 1996, p. 243). O luto, para Freud, se caracterizaria como uma reação à perda de um ente querido ou alguma abstração que 
O entre-lugar dos desaparecidos políticos em K. Relato de uma busca e

Você vai voltar pra mim e outros contos, de Bernardo Kucinski| 153

equivalesse a isso. Ainda segundo o autor, em determinadas pessoas com alguma predisposição patológica, essa mesma perda causaria melancolia, a qual, diferente do que ocorre no luto, afeta a autoestima do indivíduo.

No que diz respeito à Joana não encontramos indícios aparentes de melancolia, sua autoestima parece preservada, o que faz com que a vejamos apenas como enlutada.

Não pensem que ela seja uma louca. Nada disso. É uma mulher normal, um pouco maltratada pela vida, como toda mulher pobre, mas rija, de cabeça boa, com dois filhos e quatro netos, todos saudáveis. Joana recebe uma pensão do Estado por tudo o que aconteceu. [...] Mas faz questão de trabalhar. Além de cuidar dos netos, é atendente de uma floricultura por meio período (KUCINSKI, 2014, p. 58).

A situação é distinta quando consideramos o caso de K., pois se no luto é o mundo que se torna pobre e vazio, e na melancolia, o próprio ego (FREUD, 1996, p. 243), o pai de A. poderia ser visto como melancólico. Utilizando como parâmetro, a situação vivida quando de sua prisão na Polônia, fato que está na origem de sua posterior vinda para o Brasil, onde se radica, $K$. conclui que sua atual condição em pouco difere da anterior, pois "tudo que fizera nesses cinquenta anos não passou de um autoengano" (KUCINSKI, 2014a, p. 172). Ou seja, a dor pela morte não conclusa da filha atua como uma ferida aberta que faz com que o protagonista gradativamente vá deixando de atribuir sentido à sua existência.

Afora a melancolia, acrescenta-se em K. o terror psicológico gerado pelas inúmeras informações falsas a respeito do desaparecimento forçado de A., além do sentimento de culpa por estar tão atento aos estudos de iídiche, que não percebeu a realidade em seu entorno e o que ocorria com a vida da filha, o que o impediu de protege-la, fato que poderia ter evitado o seu desaparecimento.

Também os sobreviventes daqui estão sempre a vasculhar o passado em busca daquele momento em que poderiam ter evitado a tragédia e por algum motivo falharam. Milan Kundera chamou de "totalitarismo familiar" o conjunto de mecanismos de culpabilização desvendados por Kafka. Nós 
154 Cristina Napp dos Santos e Claudia Lorena Fonseca

poderíamos chamar o nosso de "totalitarismo
institucional".
Porque é óbvio que o esclarecimento dos sequestros e
execuções, de como e quando se deu cada crime, acabaria
com a maior parte daquelas áreas sombrias que fazem crer
que, se tivéssemos agido diferentemente do que agimos, a
tragédia teria sido abortada (KUCINSKI, 2014a, p. 168).

Ainda assim, após um ano de buscas, já sem esperanças de encontrar a filha viva ou ao menos indícios concretos de sua morte, K., consciente da necessidade de finalização dessa etapa de sua vida, se empenha em proporcionar a A. a transição de sua alma, segundo os dogmas de sua religião. Para tanto, como solução, solicita a colocação de uma lápide no túmulo a fim de que a memória da filha pudesse ser reverenciada. Acontece que K. é judeu e, segundo o que determinam os livros sagrados do judaísmo, não há a possibilidade de sepultamento sem que sejam realizados os ritos mortuários fundamentais para $\mathrm{o}$ desligamento da alma, e isso exige um corpo a ser purificado, motivo pelo qual the negam o pedido. Somado a esse argumento, acrescentam que sendo A. uma terrorista, seria indigna, não podendo, assim, descansar sua alma naquele campo sagrado. Portanto, frente a mais essa recusa, e por não encontrar meios de fazer com que a memória de A. descansasse, tampouco a sua própria ao partir, K. lamenta muito mais a nãoformalização da morte da filha do que a morte em si, o mesmo sentimento que angustiava Antunes, o qual, ao contrário de K. consegue alcançar êxito em seu objetivo.

K. sente com intensidade insólita a justeza desse preceito, a urgência em erguer para a filha uma lápide, ao se completar um ano da sua perda. A falta da lápide equivale a dizer que ela não existiu e isso não era verdade: ela existiu, tornou-se adulta, desenvolveu uma personalidade, criou o seu mundo, formou-se a universidade. Casou-se. Sofre a falta dessa lápide como um desastre a mais, uma punição adicional por seu alheamento diante do que estava acontecendo com a filha bem debaixo de seus olhos (KUCINSKI, 2014a, p. 78-79).

Assim, somando-se um fato ao outro, e a outros mais, $\mathrm{K}$. finalmente se abandona às circunstâncias, perde suas forças e vai 
O entre-lugar dos desaparecidos políticos em K. Relato de uma busca e

Você vai voltar pra mim e outros contos, de Bernardo Kucinski| 155

definhando pouco a pouco, o que causa comoção entre aqueles que o conheceram antes dos eventos trágicos vividos, e que testemunham a via crucis por ele empreendida, bem como a desintegração do homem que se extingue tal como a memória da filha que ele se vê incapaz de salvar. "Comparavam o K. de antes do sumiço da filha com o K. de depois e se condoíam. Antes, K. queria ouvir suas histórias. Agora eram eles que tinham que ouvir seu lamento" (KUCINSKI, 2014a, p.171). Por fim, antes de sua morte, quatorze meses após o desaparecimento de A., K. consegue uma entrevista com presos políticos do Barro Branco a fim de ainda tentar entender como sucedeu a morte da filha.

Armaram uma roda de cadeiras, K. sentou-se à frente. Depositou no piso a sacola e começou logo a contar a história que já havia repetido tantas vezes. Mas era como se a contasse pela primeira vez. Fitava um preso, depois outro. Tropeçava nas palavras. No meio da fala saíam palavras do iídiche. Repetia como um refrão, mein tiere techeterl, minha filhinha querida. Sentia de volta o sotaque dos primeiros dias de Brasil (KUCINSKI, 2014a, p.174).

A insistência em repetir a mesma história, repetição que não esgota a memória de A., é o que Kristeva denominou "a palavra do deprimido”, caracterizada como repetitiva e monótona (1989, p. 39). Para a autora o estado depressivo seria uma fragmentação do ego que se manifestaria na fragmentação da fala do sujeito.

$\mathrm{Na}$ impossibilidade de encadear, a frase se interrompe, esgota-se, para. Mesmo os sintagmas não chegam a se formular. Um ritmo repetitivo, uma melodia monótona vem dominar as sequências lógicas quebradas e transformálas em litanias recorrentes, enervantes (KRISTEVA, 1989, p. 39).

Considerando-se esses aspectos, acreditamos ser lícito afirmar que a repetição das mesmas histórias, bem como a fragmentação da fala de K. diante da roda de presos políticos são manifestações linguísticas motivadas pelo reconhecimento da dor da perda, situação similar a que vive Joana, que também passa a repetir-se após deixar de ter notícias de Raimundo, neste caso não através de manifestações da linguagem, mas 


\section{6 | Cristina Napp dos Santos e Claudia Lorena Fonseca}

uma repetição de comportamentos, como um ritual que cumpre há mais de vinte anos: enrolar-se em um xale e sair distribuindo moedas para os moradores de rua, questionando se algum deles percebeu algum andarilho desconhecido e de mais idade.

É como se uma força superior a fizesse se levantar automaticamente e sair errante pelas ruas à procura do marido. Quase como uma sonâmbula. Ou como se estivesse pagando uma promessa. Não sei definir, sou advogado e não psicólogo, só sei dizer que é uma necessidade psíquica dela que todos respeitamos. Inclusive os filhos (KUCINSKI, 2014a, p. 60).

Portanto, Joana permanece presa ao evento traumático, da mesma forma que K., cuja morte, ao mesmo tempo em que lhe proporciona, finalmente, descanso, ou o fim da dor, não faz com que se feche a ferida aberta pelo desaparecimento de A. e de tantos outros, vítimas das atrocidades cometidas não apenas contra indivíduos e seus familiares ou pessoas com as quais conviveram, mas sim contra a sociedade como um todo. O desaparecimento de A. segue em aberto, ilustrando as dimensões da barbárie e deixando a conta para os que ficam, como o próprio narrador, que no intuito de concluir o que o não foi possível ao pai, lança mão de estratégias narrativas para finalmente sepultar a irmã, dando fim, talvez, ao seu próprio luto. A opção pelo foco em terceira pessoa lhe confere o distanciamento necessário para ordenar os fatos e tentar entender a experiência. A obra é um ritual de luto, lápide para A., sepultada na literatura, esse campo sagrado, e é também possibilidade de pensar a alma de K. apaziguada ${ }^{39}$. Profundamente afetado ainda, segue tendo de conviver com as feridas do episódio e as investidas do sistema

\footnotetext{
${ }^{39} \mathrm{Na}$ novela Os Visitantes, ambientada no tempo presente, novas informações são agregadas à história do desaparecimento de A. Alguns leitores de K. e indivíduos mencionados no romance, além de seu próprio pai, procuram o autor para fazer críticas e questionamentos em torno da obra. Mais do que um desdobramento do primeiro livro, a novela pode ser entendida como uma autocrítica e uma discussão sobre as dificuldades em narrar o trauma ainda latente. Por tentar responder algumas questões trazidas em K., suscitar outras mais, e não se relacionar intimamente com a situação dos desaparecidos, optou-se por não o considerar neste trabalho.
} 
O entre-lugar dos desaparecidos políticos em K. Relato de uma busca e

Você vai voltar pra mim e outros contos, de Bernardo Kucinski| 157

repressivo, o qual, segundo o autor (KUCINSKI, 2014a, p. 182), continua articulado.

\section{Considerações Finais}

Tanto em K. quanto em Você vai voltar pra mim, as personagens compartilham o sofrimento de terem seus familiares mortos e desaparecidos pelo regime. Mesmo apresentando essa similaridade, cada uma das obras revela uma particularidade em se tratando de experiência do luto. Enquanto K. deixa de atribuir sentido à própria existência, Antunes providencia um enterro simbólico ao filho, ressignificando, assim, sua vida, ao mesmo tempo em que Joana nega a morte do marido. Isso se deve ao fato de que a prática do desaparecimento tem como característica o fato de criar uma situação que não é plenamente categorizável, o que o torna ainda mais cruel, pois a ausência do corpo sugere morte, mas não a confirma, deixando-a em aberto, ampliando os efeitos da violência perpetrada.

É essa não-categorização que aproxima a situação dos desaparecidos e dos sobreviventes às ideias apresentadas por Silviano Santiago na proposição do conceito de entre-lugar. O fato de A., de Roberto e de Raimundo não estarem nem vivos, nem mortos, mas estarem vivos e mortos, pode ser entendido como uma descentralização na medida em que cria uma terceira ordem no binômio vida-morte. É justamente por estarem situados nessa terceira ordem, ou margem, que os desaparecidos se situam em um entre-lugar, em uma situação em que morte e vida coexistem. Se Antunes consegue se desvencilhar e sair dessa terceira margem, K. se fixa nela por não conseguir, em função do seu estado melancólico, superar a perda da filha, morrendo assim em vida.

Em relação à situação de A., a de Raimundo e a de seus respectivos familiares é importante salientar que estas se entrecruzam, sobretudo quando consideramos que um dos empecilhos para que $\mathrm{K}$. e Joana aceitem plenamente essas mortes é a não possibilidade de sepultamento de sua filha e de seu marido, respectivamente. Isso explicita, ainda que Freud não o tenha mencionado em seu ensaio sobre o tema, a importância que a cultura ocidental atribui aos rituais fúnebres para o encerramento da etapa do luto, o qual extrapola os limites daquele que é natural, e que em $\mathrm{K}$. acaba por se transformar em melancolia, ao esvaziar de sentido a vida desse pai. 
Nesse sentido, em um momento em que as discussões acerca dos Direitos Humanos estão cada vez mais na ordem do dia, a obra de Bernardo Kucinski se faz de extrema importância, uma vez que a ficção, além de colocar em relevo as atrocidades cometidas pelo Regime Militar brasileiro, expõe de que forma esses atos ecoaram e ainda ecoam nos familiares das vítimas, sobretudo quando se trata de um caso de desaparecimento forçado.

\section{REFERÊNCIAS}

ARAÚJO LIMA, Anna Georgea Feitosa Mayer de. Estudos sobre desaparecimentos, morte, morrer e luto. RBSE - Revista Brasileira de Sociologia da Emoção, v. 11, n. 33, pp. 986-989, 2012.

BENEVIDES, Maria V. M. [Orelha do livro]. In: KUCINSKI, Bernardo. K. - relato de uma busca. São Paulo, Cosac Naify, 2014.

CORTAZAR, Julio. Alguns aspectos do conto. In: Valise de Cronópio. São Paulo: Perspectiva, 1974.

FREUD, Sigmund. Luto e melancolia, 1917. In: A história do movimento psicanalítico. Rio de Janeiro: Imago, 1996. (Edição standard brasileira das obras psicológicas completas de Sigmund Freud, 14).

KRISTEVA, Julia. Sol Negro: depressão e melancolia. Tradução de Carlota Gomes. -Rio de Janeiro: Rocco, 1989.

KUCINSKI, Bernardo. K. - relato de uma busca. São Paulo, Cosac Naify, 2014a.

. Você vai voltar pra mim e outros contos. São Paulo: Cosac Naify, 2014b.

. Entrevista a Yasmin Taketani. Recife: Suplemento Pernambuco, 05 Set 2016. Disponível em: <http://www.suplementopernambuco.com.br/entrevistas/1671entrevista-bernardo-kucinski.html>. Acesso em: $01 \mathrm{fev} 2018$.

RODOLPHO, A. L. Rituais, ritos de passagem e de iniciação: uma revisão da bibliografia antropológica. Estudos Teológicos, São Leopoldo, v.44, n. 2, p. 138-146, 2004. Disponível em: <http://periodicos.est.edu.br/index.php/estudos teologicos/article/v iew/560>. Acesso em: 01 fev 2018.

Recebido em: 18/02/2018

Aceito em: 29/03/2018 